\title{
Social Language as an Indicator of Social Presence in Online Journalism
}

\author{
Dr. Mahmoud Hamdy ${ }^{*}$
}

\begin{abstract}
:
A quasi-experiment tests six hypotheses predicting that social language would increase the feeling of social presence among readers of online journalism. Participants read eight articles in one of eight Conditions created by four manipulations: use or absence of one of the four aspects of social language.

T- Test, ANOVA \& ANCOVA were used to test the effects of the manipulations on social presence among readers. It was found that social language increased social presence among readers in the four manipulations. The effect of both interactive language and cohesive language is stronger than the effect of affective language. Social language can compensate the lack of nonverbal cues in face to face communication and that can help online journalism to encourage readers to participate and interact with journalists.
\end{abstract}

\section{Keywords:}

Social language - Participation - Interactivity - Social presence.

\section{Introduction:}

Although "media language" is not an entirely new field in linguistics, the revision of related literature shows a significant lack of focus and direction in Egypt and Arab world comparing to the foreign countries, especially the studies which concentrate on the language of online journalism. If the power of the media can be of a crucial importance in changing the lives of people,

* Lecturer of Journalism, Mass Communication Department, Faculty of Arts, ElMinia University.

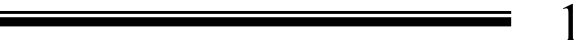


the language has the great part of media power. So, the studying of media language - especially, the language of new media - is of a great importance.

This study concentrates on the social language which can be one of the most important features of the language of online journalism that can generate the sense of social presence among readers.

Martin Conboy stated that "the twentieth-century newspapers' language was shaped by a wave of technologies competing with the newspaper as the prime provider of topical information about the world. First radio, then television, satellite and most recently the internet have all forced newspapers to alter the structure and address of their language as they bid to retain a profitable and influential share of the market for news and entertainment" ${ }^{(1)}$.

In an early study Jay Rosen stated that: "To develop the journalism ability to compete the "citizen Media", journalism should transform news from a "lecture" into a "conversation"”(2), and that what Conboy assured as he said that "In newspapers today, we are witnessing the latest linguistic accommodation to changing social and commercial pressures. Newspapers have always striven to provide an elaborated form of conversation with their audiences, to be something more than a dry account of the events of the day. What they are now pressed to do is to provide a version of that daily conversation in an environment that has many other technologies competing to provide that sense of communal voice". ${ }^{(3)}$

As we know the most important feature of the internet is its interactivity which narrows the distance between readers and journalists. On the other hand, the development of the blogs and the online social networks made radical changes in the 
environment of journalism as journalists became aware to be sociable with their readers to be able to compete with these new media.

The rising popularity of the Internet and related technologies has led to increased research into the language form and style in that medium.

Clifford Nass \& Youngme Moon said "There are acknowledged limitations in online communication. Body language, facial expressions, and variations of voice intonation are simply unavailable" ${ }^{(4)}$, and Andrew Potter added "These limitations influence the use of language in an online environment, and conversely, language may be adapted to compensate for the online constraints"(5). Some researchers confirmed that there should be interactive rhetoric for computer mediated communication to succeed and achieve its functions". (6)

In my research, I try to approve that Social language is an important method for achieving interactive rhetoric in computer mediated communication and generating the social presence sense among readers of online journalism.

Kraut, et.al. (1998) indicated that "working within an online environment can be an isolating experience if the participants are unable to establish social ties with one another". ${ }^{(7)}$

Recommended activities for creating social presence include activities such as providing feedback, sharing personal experiences, and using humor. Some researchers confirmed that in an online environment, all of these activities can be accomplished exclusively through the use of language. ${ }^{(8)}$

If the writers use the language effectively that can help them in sharing their viewpoints with their readers, and that what Dan 
Gillmor confirmed when he said "the evolution-from journalism as a lecture to journalism as a conversation or seminar-will force the various communities of interest to adapt. Everyone, from journalists to the people we cover to our sources and the former audience, must change their ways". ${ }^{(9)}$

In his experimental study Hamman Concluded that "In the age of social media, journalists should be sociable and they can narrow the institutional distance between them and their readers through social language, as they should use social language to attract and to be near to their readers. He added that Journalists' sociability means that they should step out from behind their keyboards and become real people with recognizable faces and personalities". ${ }^{(10)}$

\section{Online Journalism, Social Language and social Presence:}

One of the most important features of journalistic language is its ability to develop to adapt to its audience from one side, and to adapt to the new technology from the other side as Cotter said "Investigative aspects of news organizations' language use and usage ideologies overtime and across situation diachronically and synchronically - provides a productive glimpse into the dynamics of innovation and stability that underpin language and genre change. Language changes occur either incrementally over time or consciously at a specific point in time. The changes particularly evident on the journalistic level being delivery style and genre form. New technologies, particularly the web and digital recording options, are also playing a role in altering discourse forms". ${ }^{(11)}$

That what starts to occur in the environment of online journalism as it should be more sociable to compensate the lack of social presence, and that what I concentrate on here as there 
are no studies - until now - about the role of social language in generating social presence in Arab online journalism.

In order to achieve a clear understanding of social language on the public, the study benefits from sociolinguistics, as it is one of the available linguistic methods that can help me - to a great part - to achieve the goals of my study.

Sociolinguistics is the study of the effect of any and all aspects of society, including cultural norms, expectations, and context, on the way language is used. Sociolinguistics differs from sociology of language in that the focus of sociolinguistics is the effect of the society on the language (the effect of the internet in our study on the language of online journalism), while the latter's focus is on the language's effect on the society. Sociolinguistics overlaps to a considerable degree with pragmatics. $^{(12)}$

Research into social presence (making personal characteristics visible to the community) in online educational communities, in particular, has focused on the use of text-based social behaviors - which Brian has called "social language" "(13) - to convey social messages outside of the normal coursework that may facilitate the success of cognitive presence and teaching presence. $^{(14)}$

According to Rourke et al., social presence can be classified through a series of indicators (text-based behaviors or social language) that fit into the following categories: affective, interactive, and cohesive categories.

These categories are linguistic behaviors, and consisted of a lot of indicators as the following: ${ }^{15}$

- The affective category: expression of emotions, use of humor, and self-disclosure (revealing more about oneself to 
others, This may include, thoughts, feelings, aspirations, goals, failures, successes, fears, dreams as well as one's likes, dislikes, and favorites).

- The interactive category: continuing a thread, quoting from others' messages, referring explicitly to others' messages, asking questions, complimenting and expressing appreciation or agreement, using someone's first name.

- The cohesive category: vocatives, addresses, making reference to the group by using inclusive pronouns (using inclusive terminology such as "we"), and using phatics (words used to share feelings or to establish a mood of sociability rather than to communicate information or ideas.) and salutations.

The definitions for each indicator, as well as examples of each are summarized in Table 1. 


\section{Table 1}

Categories, indicators, and examples of social presence

\begin{tabular}{|c|c|c|c|}
\hline Category & Indicators & Definition & Example \\
\hline \multirow{3}{*}{ Affective } & $\begin{array}{l}\text { Expression } \\
\text { of } \\
\text { emotions }\end{array}$ & $\begin{array}{l}\text { Conventional expressions of } \\
\text { Emotion, or unconventional } \\
\text { expressions of emotion, } \\
\text { includes repetitious } \\
\text { punctuation, conspicuous } \\
\text { capitalization، emoticons. }\end{array}$ & $\begin{array}{l}\text { How can one learn } \\
\text { without making } \\
\text { errors??????? } \\
\text { Impossible! :) }\end{array}$ \\
\hline & $\begin{array}{l}\text { Use of } \\
\text { humor }\end{array}$ & $\begin{array}{l}\text { Teasing, cajoling, irony, } \\
\text { understatements, sarcasm }\end{array}$ & $\begin{array}{l}\text { Not a Webster's } \\
\text { definition, but alas } \\
\text { I am not a Webster! }\end{array}$ \\
\hline & $\begin{array}{l}\text { Self- } \\
\text { disclosure }\end{array}$ & $\begin{array}{l}\text { Presents details of life outside } \\
\text { of } \\
\text { class, or expresses } \\
\text { vulnerability }\end{array}$ & $\begin{array}{l}\text { I feel like I never } \\
\text { have time to do } \\
\text { anything the way I } \\
\text { want to. }\end{array}$ \\
\hline \multirow[t]{4}{*}{ Interactive } & $\begin{array}{l}\text { Continuing a } \\
\text { thread }\end{array}$ & $\begin{array}{l}\text { Using reply feature of } \\
\text { software } \\
\text { rather than starting a new } \\
\text { thread }\end{array}$ & $\begin{array}{l}\text { In Reply to: } \\
\text { Preliminary Journal } \\
\text { Entry posted by } \\
\text { MB on September } \\
04, \quad 2003 \text { at } \\
22: 02: 38:\end{array}$ \\
\hline & $\begin{array}{l}\text { Quoting } \\
\text { from } \\
\text { others' } \\
\text { messages }\end{array}$ & $\begin{array}{l}\text { Using software features to } \\
\text { quote others' entire message } \\
\text { or cut-and pasting selections } \\
\text { of others' messages }\end{array}$ & $\begin{array}{l}\text { "They know I } \\
\text { demand a lot and } \\
\text { they are really } \\
\text { starting to respond } \\
\text { the way I want } \\
\text { them to." }\end{array}$ \\
\hline & $\begin{array}{l}\text { Referring } \\
\text { explicitly } \\
\text { to others' } \\
\text { messages }\end{array}$ & $\begin{array}{l}\text { Direct references to contents } \\
\text { of others' posts }\end{array}$ & $\begin{array}{l}\text { This issue of time } \\
\text { also caught my eye } \\
\text { and thoughts. . }\end{array}$ \\
\hline & $\begin{array}{l}\text { Asking } \\
\text { questions }\end{array}$ & $\begin{array}{l}\text { Students ask questions of } \\
\text { other students or moderator }\end{array}$ & $\begin{array}{l}\text { I enjoyed reading } \\
\text { this. Keep up the } \\
\text { good work!! }\end{array}$ \\
\hline
\end{tabular}




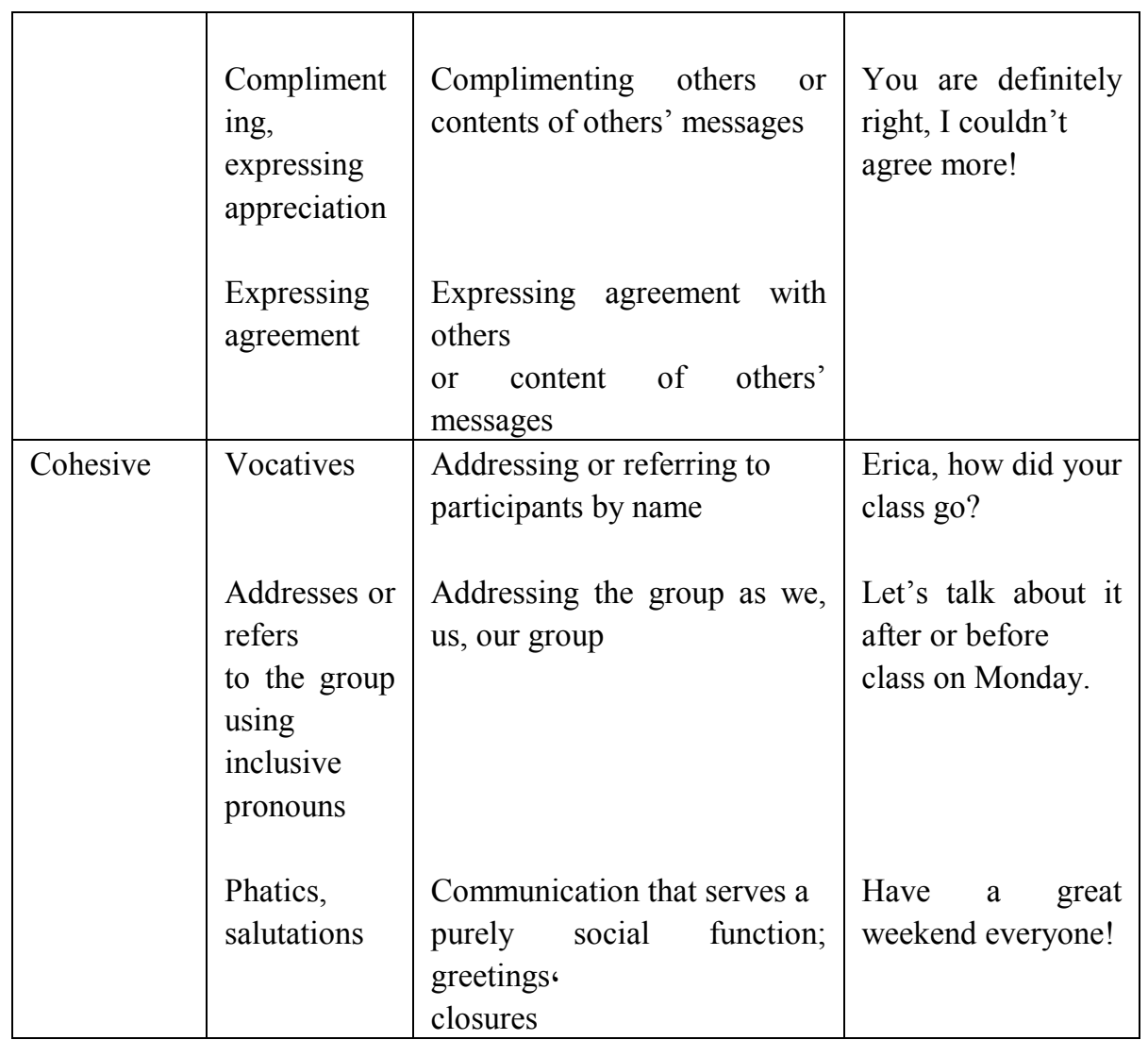

We should note that the researchers of Online Education explore these indicators in the students' comments to know if there is social presence among students or not, but in this study we try to know to what extent this social language - if it is included in articles - can generate the sense of social presence among readers, and their feelings that the writers are speaking to each one of them directly.

Concerning social presence, I build on the definition of Garrison, et al. "the ability of learners to project themselves socially and emotionally as 'real' people into a community of learners" and may facilitate the success of cognitive presence . Social presence, therefore, engages groups in interaction and communication and thus sustains and furthers critical skills". ${ }^{(17)}$ 
In case of online journalism, social presence can be defined as "the ability of journalists to project themselves socially and emotionally as 'real' people into a community of participators (the readers) and that may facilitate the success of interaction among them and construct a reasonable public opinion about salient issues".

\section{Literature Review:}

A lot of studies explored social presence specially, in the fields of "computer mediated communication" (CMC) and "online education" or what is known as "distance education", and most of it confirmed that social presence's role in distance learning and (CMC) is significant, and its ignorance can be catastrophic, as the lack of cues for the physical presence of others in an online environment requires designers and communicators to account for and construct replicates of these cues.

Walther (1992) argued that social relationships could stimulate changes in discourse as well. In examining text-based CMC (e-mails) of conference participants, Walther found that participants began developing impressions of other participants from their communications. These impressions developed into visual interpretations of the other, developed a sense of intimacy and identification between participants, which led to greater perceptions of social presence. ${ }^{(18)}$

Young Choi made a close examination of the effects of social (language) and physical distance on the global communication networks revealed that these two factors played important roles in global communication networks. The results of this study showed that language similarities/differences (whether or not its citizens spoke the four languages - English, German, French, and Spanish) were significantly related to the 
structure of the four global communication networks, that is telecommunication, written, physical, and face-to-face communication, represented by telephone, mail, trade, and transportation networks respectively. There were also statistically significant relationships between a country's physical location and language similarities/ differences and the structure of the four global communication networks. ${ }^{(19)}$

Murphy \& Collins (1997) concluded that users seem to compensate for the communicative lack of written discourse with linguistic inventions and adaptations, in order to express the meta - communicational features of non-verbal communication with appropriate orthographical strategies (e.g., emoticons, typographical marks and other textual features, including the use of capital and lowercase letters, ellipsis, exclamation marks, as well as typing errors). ${ }^{(20)}$

A number of researchers have investigated discourse and interaction differences between pen-and-paper journals and electronic journals. Wang (1998), for example, conducted a qualitative case study comparing e-mail dialogue journals with traditional pen and paper and found that the students in the email group wrote more informally and casually than did the students in the paper-and-pencil group as if they were holding a conversation". (21)

Danchak et.al., founded that a higher degree of familiarity and intimacy in content, style, structures, and timing of the exchanged postings would not only be a linguistic adaptation to incorporate colloquial and informal registers, but could also strike the balance between the features of the medium and an acceptable level of immediacy. ${ }^{(22)}$

Abrams (2001) noted that computer-mediated communication (CMC) journals assisted students in developing 
interaction skills more than during pen and paper group journal assignments, perhaps due to their more private and intimate nature. $^{(23)}$

Stein and Wanstreet (2003) suggest that if social presence is high in a learning group, there will be better placed to substitute technology mediated communication for face to face communication. ${ }^{(24)}$

In his research Steve Wheeler (2005) argued that social presence is an important feature of any successful learning activity, particularly within digital learning environments (DLEs). He also argued that social presence and several other key factors such as immediacy of dialogue and student tenacity and autonomy are useful predictors of student satisfaction in technology supported distance education. ${ }^{(25)}$

Although there are many studies about social language and social presence in online education, there is still a lack of studies about social language in online media studies.

Brian Hamman( 2006) made an important study in this field, it was an experiment tested hypotheses predicting that that the use of social behaviors (social language and personal photos) does, in fact, increase the social presence of the reporters, and that this social presence in turn leads to the increased participation on a news website and engagement with the readers as it is intended, and finally, readers of news sites with more socially present reporters perceive the articles on that site and the media organization to be more credible. ${ }^{(26)}$

Participants read four news articles in one of four conditions created by crossing two manipulations: use or absence of social language, and use or absence of a reporter photograph, both designed to increase feelings of social presence. Repeated 
measures ANCOVA was used to test the effects of the manipulations on social presence and regressions were used to test the effects of social presence on credibility and participation.

In the first part of the experiment, it was found that social language increased social presence, but use of the photograph had no effect. In turn, social presence increased an expressed intent to participate on the news website, but did not result in an actual increase in participation. Social presence also significantly hurt credibility.

Wolitzky (2014) has confirmed in her study about affective language and attitude towards public policy the impact of emotionally-valenced introductory sentences on judgments of public policy. A cross-sectional New York City sample of 367 Englishspeaking adults completed anonymous questionnaires, in which they evaluated written statements by hypothetical candidates for public office. Political messages pertained to issues of energy and immigration reform, and varied only in the emotional quality of their introductory sentences. Results indicated relevant differences in the impact of the affective introductions, associated with issue, policy condition and, most notably, political party. ${ }^{(27)}$

\section{General Comments:}

I noticed that in time many studies explored the relation between social presence and social language in E- Education, few studies give attention to this topic in the field of online journalism.

Although the importance of Brian's study, he didn't concentrate on all the three domains of social language (Affective domain, interactive domain, and cohesive domain) as he tested the effect of inclusive pronouns (like : we and us), and 
this is one feature of cohesive domain, but in my study, I explore the relation between each domain of social language and the feeling of social presence among readers and if there is any differences among these domains of social language in generating social presence or not.

I noticed that researchers of E- Education see that technology can generate social presence which can be reflected by language which users use during their interaction, and they used social language to measure the development of social presence over time. But for Brian's study, he confirmed that social language can generate social presence among readers.

In my research I concentrate on the role of social language through these three dimensions (Affective, Interactive, and Cohesive) in generating the sense of social presence in Arab online journalism.

\section{Social Presence Theory:}

Social Presence Theory was developed by the social psychologist John Short, et. al.(1976). The idea is that a medium's social effects are principally caused by the degree of social presence which it affords to its users. Social presence is meant a communicator's sense of awareness of the presence of an interaction partner. This is important for the process by which man comes to know and think about other persons, their characteristics, qualities and inner states, thus increased presence leads to a better person perception. ${ }^{(28)}$

The theory was developed based on a large amount of empirical research, much of which highlighting differences in the use of the telephone and face-to-face media in particular types of tasks, such as the negotiation task. 
Short, et. al.(1976) first defined social presence as "the degree of salience of the other person in the interaction and the consequent salience of the interpersonal relationships" or, more informally, "the degree to which someone is perceived as a 'real person $^{\text {(29) }}$. They related the concept to Argyle and Dean's concept of intimacy, which predicted an equilibrium of approach and avoidance and Wiener and Mehrabian's concept of immediacy, defined as the degree of psychological distance between two communicators.

Though the terms are all closely related, Short et. al. distinguished social presence from immediacy and intimacy by saying it was a property of a particular medium, rather than a psychological condition. It could be said that social presence was a measure of the amount of immediacy and intimacy that any given medium could support.

The term was soon after associated with the concept of media richness, according to which social presence is a quality of the communication medium itself. Communication media endowed with more bandwidth (e.g., audio-video equipment) would convey more social presence and vice versa. ${ }^{(30)}$

Short, et. al.(1976) conducted examinations of different media to see to what extent users experienced each other as 'real' people (rather than just vague presences) at the other end of impersonal communication devices. They argued that the social presence of a medium varied according to the number of social cues it offered. Channels lacking in cues, such as audio and text, would have lower social presence because they lacked capacity to communicate the amount of social information included in richer media and face-to-face communication. They theorized that people would choose a medium that was appropriate for different types of communication: high cue 
media such as face-to-face for highly social situations, or textbased media for more informational exchanges. ${ }^{(31)}$

The theory was developed based on a large amount of empirical research, much of which highlighting differences in the use of the telephone and face-to-face media in particular types of tasks, such as the negotiation task. As Social interactions are dynamic and depend heavily on verbal and nonverbal communication, face-to-face communication is richer than telephone communication.

The intensity of our sense of the social presence of others depends on the particular media in use. This, in turn influences our behavior by how much we experience others as breathing, thoughtful, emotional beings with whom we might share some degree of empathy. When Short was first developing this theory he was largely pre-occupied with the influence of the telephone. Today, social presence is a term that pops up in the area of computer-mediated communication, distance education and online journalism. ${ }^{(32)}$

Social presence theory was developed at a time when computer-mediated communication as we know it today was yet to be conceptualized, let alone implemented through computers connected via the Internet. In spite of that, the theory has influenced much computer-mediated communication research over the years.

As computer-mediated communication has evolved a more relational view of social presence has emerged. Social presence has come to be viewed as the way individuals represents themselves in their online environment. ${ }^{(33)}$ It's a personal stamp that indicates that the individual is available and willing to engage and connect with other persons in their online community. Social presence is demonstrated by the way 
messages are posted and how those messages are interpreted by others. Social presence defines how participants relate to one another which in turn affects their ability to communicate effectively. ${ }^{(34)}$

Trying to define social presence is a difficult matter as researchers are not in agreement themselves over what this phenomenon encompasses. There is no consistent definition for social presence within research literature yet. Social presence has been defined as "a measure of the feeling of community that a learner experiences in an online environment". ${ }^{(35)}$ Those interested in social responses to computers define social presence as an illusory projection of social expectations and behaviors onto non-social actors. ${ }^{(36)}$ Other researchers have defined social presence as the awareness of others in an interaction combined with an appreciation of the interpersonal aspects of that interaction. ${ }^{(37)}$

Gunawardena (1995) argued that social presence varied in perception and was a subjective issue based upon objective qualities. ${ }^{(38)}$

Personal communication researchers have identified three relevant dimensions of social presence: (1) source attention, defined as the degree to which the source is focused on relative to other cues, (2) co-presence, or the feeling of existing with the person, and (3) mutual awareness or psychological involvement - the feeling of being "known" by the other. ${ }^{(39)}$

Social presence theory classifies different communication media along a one-dimensional continuum of social presence, where the degree of social presence is equated to the degree of awareness of the other person in a communication interaction. ${ }^{(40)}$ According to social presence theory, communication is effective if the communication medium has the appropriate social 
presence required for the level of interpersonal involvement required for a task. On a continuum of social presence, the faceto-face medium is considered to have the most social presence and written, text-based communication the least.

\section{Criticism:}

While Short et al. were aware of the social undertones of language; they did not anticipate that users of a communication medium would be able to modify their behavior in order to maintain a high level of sociability. They thought that each medium had an upper bound on how sociable it could be - of how much immediacy and intimacy it could sustain.

Contrary to what Short et al., originally theorized, however, current researchers define social presence not as a characteristic of the medium, but rather how participants use the medium to communicate. ${ }^{(41)}$ In this new paradigm, social presence is defined as a "subjective" measure of the sociability of a communications medium which is derived from a combination of a medium's interactivity (an objective measure of sociability) and whether that interactivity was realized. For example, while it may be fair to say that communication through a business letter has fewer available social cues than communication in person; this does not necessarily predict that readers of the letter will experience lower feelings of social presence. It would depend on the contents of both the letter and in-person communication.

On the other hand, a large body of research into early textbased games and chat rooms has demonstrated that rich social relationships and communities develop in even the simplest textbased environment ${ }^{(42)}$, and some researchers found that online communities can connect individuals to exchange emotional support and encouragement on everything like a classroom homework assignment. ${ }^{(43)}$ 
Other researchers assured that people can develop more intimate friendships through mediated communication than they would have in only a face-to-face setting. ${ }^{(44)}$ Users of instant messaging programs, for example, choose the mediated communication environment because they are able to comfortably have more intimate conversations than otherwise possible. ${ }^{(45)}$

The question now is how does this intimacy develop in a communication environment lacking in social cues? Walther (1992) argued that communicators would substitute textual cues for non-verbal cues lacking in CMC in order to maintain an equilibrium of sociability. ${ }^{(46)}$

Researchers have identified numerous examples of this cue substitution. ( ${ }^{(4)}$ Users of instant-messaging programs, for example, use emoticons (such as smiley faces :-)) and short-hand text (such as LOL for laugh-out-loud) to convey emotion and other behaviors. (48) Participants in online educational communities often use humor, referential posts, and share personal anecdotes unrelated to the course work. ${ }^{(49)}$

Taken together, these behaviors can develop into sophisticated social norms that can either form boundaries ${ }^{(50)}$ or encourage participation in online communities. ${ }^{(51)}$

Users seem to compensate for the communicative lack of written discourse with linguistic inventions and adaptations, in order to express the meta communicational features of nonverbal communication with appropriate orthographical strategies (e.g., emoticons, typographical marks and other textual features, including the use of capital and lowercase letters, ellipsis, exclamation marks, as well as typing errors). ${ }^{\left(5_{2}\right)}$ In this way, a higher degree of familiarity and intimacy in content, style, structures, and timing of the exchanged postings would not only 
be a linguistic adaptation to incorporate colloquial and informal registers, but could also strike the balance between the features of the medium and an acceptable level of immediacy. ${ }^{\left({ }_{3}\right)}$

As the ability of people to work together effectively in groups is central to social presence theory, so this theory is of great interest and provides a theoretical focus for studying social presence in online journalism.

Building on this criticism we explore to what extent can social language substitute the lack of nonverbal cues (e.g., facial expression, posture, gesture, proximity) in online journalism, and if it can generate the sense of social presence of writers among readers which is important to encourage readers to interact with their writers and participate their ideas and opinions.

As this study tries to explore the role of social language in generating social presence among readers of online journalism, and trying to achieve this general goal, I explored the role of the different types of social language in generating social presence among readers as following:

- The role of affective language in generating social presence among readers of online journalism.

- The role of interactive language in generating social presence among readers of online journalism.

- The role of cohesive language in generating social presence among readers of online journalism.

\section{Research Hypotheses:}

In terms of the previous theoretical framework and literature review, the research seeks to investigate the following hypotheses:

H1: there are significant differences between readers of an article with an affective language and readers of the same article 
without an affective language according to their levels of social presence.

H2: there are significant differences between readers of an article with an interactive language and readers of the same article without an interactive language according to their levels of social presence.

H3: there are significant differences between readers of an article with a cohesive language and readers of the same article without a cohesive language according to their levels of social presence.

H4: there are significant differences between readers of an article with all the three types of the social language and readers of the same article without social language according to their levels of social presence

H5: there are significant differences among the four experimental groups who are exposed to different types of social language according to their levels of social presence.

H6: there are significant differences between readers of articles with social language and readers of the same articles without social language according to their levels of social presence after excluding the effect of both of introversion and involvement.

\section{Methodology:}

I made a semi - experiment to test these hypotheses, in which Participants read eight articles in one of eight Conditions created by four manipulations: whether the article had an affective language or not/ whether the article had an interactive language or not/ whether the article had a cohesive language or not/ whether the article had the three categories of social language or not. 
To avoid the effect of different types of social language on the same reader, I did my experiment along four stages. In the first stage, I tested the effect of affective language on social presence. In the second stage, I tested the effect of the interactive language - in another article - on social presence. In the third stage, I tested the effect of cohesive language - in another article - on social presence. In the fourth stage, I tested the effect of the three categories - in another article - on social presence.

In each stage, I used the style of post comparison design between two groups (experimental group and control group) each group consisted of 30 students.

In each article of the four articles which I used in my experiment, I put in my consider that each article must save the same characteristics - to a great extend - after making the language manipulation in it, especially the length of the article, the length of sentences, the number of words.

\section{The manipulations of the four articles were as follows:}

1- The first article: it belongs to Galal Amer a humorist writer titeld "time of dusk". He used three forms of affective language in it; use of humor, self-disclosure, and expressing of emotions. Distributed in Al Masry Alyoum newspaper on 22 Feb. 2011. The same article has been written again without affective language but I saved the same ideas, and the same structure.

2- The second article: it belongs to Osama Haikal a political writer titeld "Waiting the security" Distributed in Al MasryAlyoum newspaper on 5 March 2011. I manipulated it to include interactive language especially "quoting from others' messages, expressing agreement, and asking 
questions" the other copy has been written without interactive language.

3- The third article: it belongs to Waheed Abde AlMageed a political writer titeld "to avoid a false referendum" Distributed in Al MasryAlyoum newspaper on 5 March 2011. It was out of any social language and I manipulated it to include cohesive language, I used (we and us) all over the article and I concluded it by the phatic "all of you the Egyptians deserve a civil and respective constitution".

4- The fourth article: it belongs to Belal Fadl a humorist writer titeld " AboZarr appears in front of Parliament". Distributed in Al MasryAlyoum newspaper on 22 Jan. 2011. It has been manipulated to include the three types of social language one time and to be out of any social language another time.

I designed - by the help of an expert - an interface of a web site of an online journalism and named it (The future), and I saved the same design in the four stages. In each stage, I put each article on the upper left side on the front page with its manipulation in a copy and without manipulation in another copy.

I made my experiment during March/April 2011. This gave me a chance to make a separation between each stage. In each stage, I made two groups (experimental group and control group) each one consisted of 30 students from the department of Mass Com. - ElMinia University especially third and fourth levels. Some students helped me by getting their laptops as I made my experiment offline. In each stage, I copied the target design on the students' labtops before doing it and I deleted it after making the experiment directly to avoid the effect of each stage on the other one. 
I used (two tails t- test) to explore the differences between each experimental group (who read the manipulated article) and each control group (who read the same article without manipulation) in all the stages of the experiment and I used (ANOVA) to know the variance among the four experimental groups. Finally, I used (UNCOVA) to exclude the effect of control variables which I explain in the coming part in this research.

After reading each article, the participants filled out a written questionnaire with questions about social presence, involvement, introversion, and here is the explanation of measuring the dependent variable and the control variables.

\section{Dependent Variable:}

\section{Social Presence:}

This study used a scale developed by Tamborini (2005), which tested the dimensions of social presence which are: source attention, mutual awareness, and co-presence. The scale consisted of eight 7- item Likert-style questions. Factor analysis (by Principal componants of Hottelling) followed by Varimax rotation yielded two factors. The eigen value for the first factor was (4.247) and explained (32.17\%) of the variance. This factor contained five items: "I paid more attention to the reporter than the story," "When I read the story I imagined the reporter writing it," "I felt like I got to know the reporter," " I felt like the reporter was in the room with me," and "I was aware of the reporter while reading the article."

The eigen value for the second factor was (2.53) and explained $(15.76 \%)$ of the variance. the second factor contained three items ("I felt like the reporter was talking directly to me," "I felt like the reporter was thinking about readers like me when 
he or she wrote the article."), and "I felt present with the reporter".

Each item of the scale is correlated with the whole measure at high level of significance (0.001) which means a great internal consistency of social presence measure. The Guttman split half between odd and even items was (0.87) and that means the measure of social presence is reliable.

\section{Control Variables:}

\section{Involvement:}

Some studies confirmed that Involvement (The fact or condition of being involved with or participating in something) in the content has moderated a variety of perceptual responses to media, including social presence ${ }^{(54)}$. To measure involvement, I used a seven-point semantic differential scale developed by Zaichowsky $(1985)^{(55)}$, as I asked respondents to use a 7-point semantic differential scale to rate their article from 1 (unimportant to me) to 7 (important to me), 1 (of no concern to me) to 7 (of concern to me), 1 (irrelevant to me) to 7 (relevant to me), 1 (means nothing to me) to 7 (means a lot to me), 1 (useless to me) to 7 (useful to me), and 1 (insignificant to me) to 7 (significant to me).

\section{Introversion:}

Some students may be more sociable than others, and this characteristic may affect on their sense of social presence, so I measured the level of extroversion-introversion for each student.

The trait of extroversion - introversion is a central dimension of human personality theories. Thompson (2008) stated that "extraversion tends to be manifested in outgoing, talkative, energetic behavior, whereas introversion is manifested in more reserved and solitary behavior". ${ }^{(56)}$ 
I used the introversion scale which was developed by McCroskey. ${ }^{(57)}$ This scale consists of 12 items and each student indicates whether he/she believes each statement applies to him/her. Presume: $3=$ Yes; $2=$ Undecided; and $1=$ No.

To determine the score of each student on the introversion scale, I completed the following steps:

1 - I added the scores of item 1 and item 3.

2- I added the scores of items 2 and $4-12$.

3 - I completed the following formula:

Introversion $=40+$ Total from step $1-$ Total from step 2 .

The lowest score is 12 and the biggest score is 36 . Scores above 28 indicate high introversion, scores below 20 indicate low introversion, and scores between $20-28$ indicates moderate introversion.

\section{The items included the following:}

1. Are you inclined to keep in the background on social occasions?

2. Do you like to mix socially with people?

3. Are you inclined to limit your acquaintances to a select few?

4. Do you like to have many social engagements?

5. Would you rate yourself as a happy-go-lucky individual?

6. Can you usually let yourself go and have a good time at a party?

7. Would you be very unhappy if you were prevented from making numerous social contacts?

8. Do you usually take the initiative in making new friends?

9. Do you like to play pranks upon others?

10 . Are you usually a "good mixer?" 
11. Do you often "have the time of your life" at social affairs?

12. Do you derive more satisfaction from social activities than from anything else?

Finally, I made a questionnaire consisted of all the variables of my study, and I made some changes on it by the help of a professor in the department. ${ }^{(58)}$

\section{Results and discussion:}

\section{1- Affective language:}

The first hypothesis predicted that there are significant differences between readers of an article with an affective language and readers of the same article without an affective language according to their levels of social presence, and this hypothesis was tested by Independent - Samples T - test, as I made a comparison between two groups (experimental group and control group) the first group read an article that had been written by affective language, and the other group read the same article without affective language (non social language) and after answering a questionnaire, I used T-test to know if there are differences between the two groups or not as follows:

The normality of the two groups has been approved by the test of "Kolmogorov -Smirnov" (p. Value > 0.05) and the homogeneity (Equal variances) was approved too by Levene's Test for Equality of Variances as $(\mathrm{F}=0.004$, Sig. $=0.948)$. T- test emphasized that there are significant differences between the experimental group and the control group as $[\mathrm{T}=9.684$, $\mathrm{df}=58$, Sig. $(2$-tailed $)=0.001($ less than 0.05$)]$. 
Table 2

Independent Samples Test

Affective language and social presence

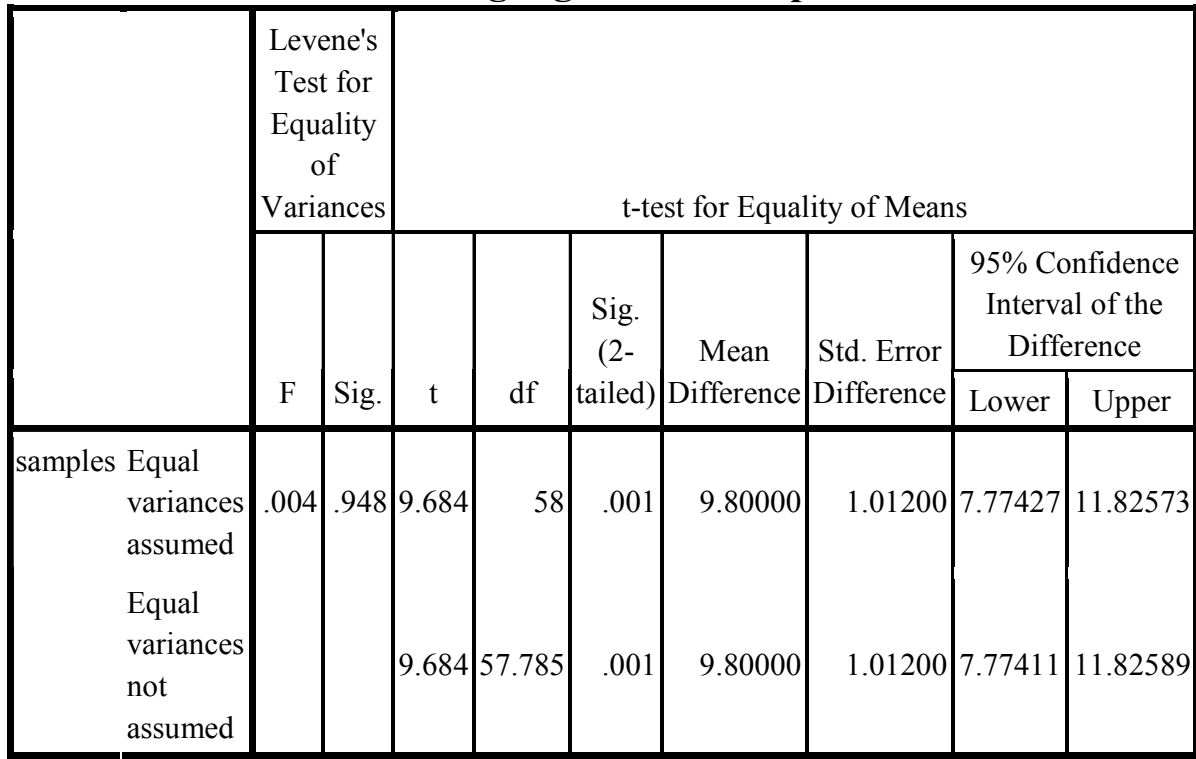

This result confirmed that the affective language can generate the sense of social presence among readers as the Mean of social presence among experimental group was (22.1) on the scale of social presence, but the Mean of social presence among control group was (12.3).

Table3

Group Statistics

\begin{tabular}{|c|r|r|r|r|}
\hline code & $\mathrm{N}$ & Mean & Std. Deviation & Std. Error Mean \\
\hline \multirow{2}{*}{ samples experimental group } & 30 & 22.1000 & 4.03733 & .73711 \\
control group & 30 & 12.3000 & 3.79791 & .69340 \\
\hline
\end{tabular}

According to the experimental group, T- test confirmed that there are significant differences between males and females 
regarding to the role of affective language in generating social presence. $[\mathrm{T}=-3.027, \mathrm{df}=28$, Sig. $(2$-tailed $)=.005]$.

Table 4

Independent Samples Test

Affective language and gender

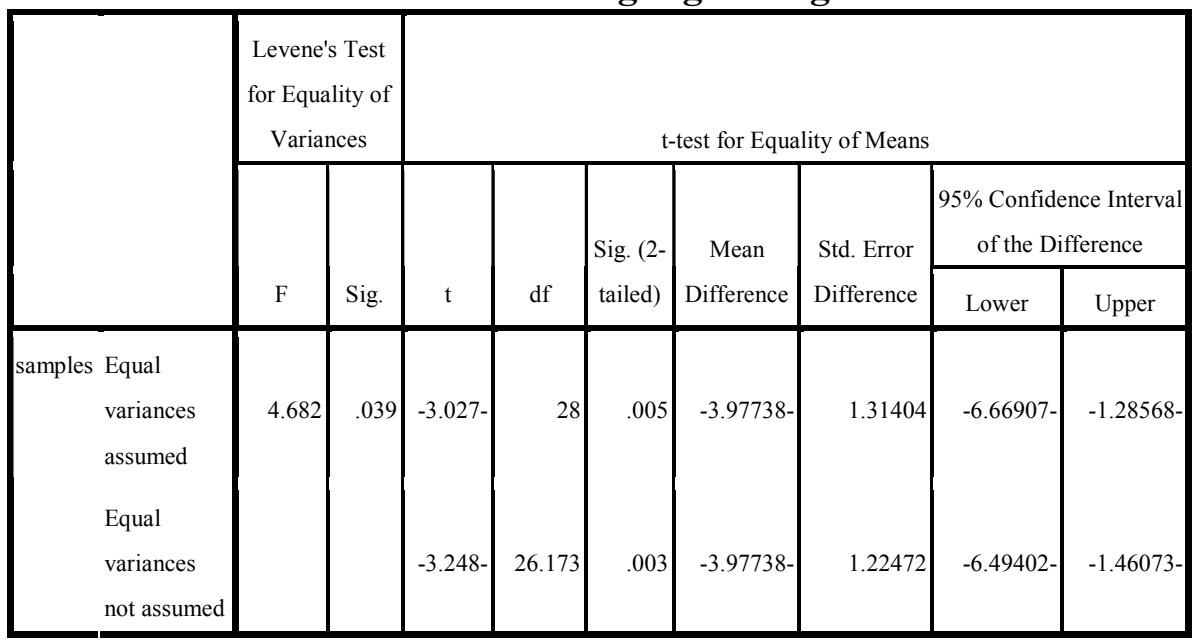

The Mean of social presence among females was (23.8235) and it was bigger than the Mean of social presence among males (19.8462) and that means females can be affected by affective language more than males.

Table 5

Group Statistics

\begin{tabular}{|c|c|c|r|r|}
\hline gender & N & Mean & Std. Deviation & Std. Error Mean \\
\hline samples male & 13 & 19.8462 & 2.40992 & .66839 \\
female & 17 & 23.8235 & 4.23136 & 1.02626 \\
\hline
\end{tabular}

This result agrees with what (Wolitzky: 2014) has confirmed in her study about affective language: "affective, rather than cognitive, material is the principal driver of human behavior and decision-making, and that most, if not all, of the 
evaluative process occurs outside of conscious awareness, and she added that Political messages that do not differ in their general underlying policy positions can vary greatly in their impact, depending on what values, images and feelings they evoke". ${ }^{(59)}$

Ochs \& Schieffelin (1989) said that there are two major channels to covey affect - nonverbal and verbal. Nonverbal channels such as facial expressions, gestures, body orientation and the like. Verbal channels which are linguistic means available to language users to index particular kinds of affect. They confirmed that the affect cues from verbal channel play the same role as visual cues, and languages of the world are responsive to this human need to express assess affect. Further, they are responsive at all levels of linguistic structure. Affect permeates the entire linguistic system. Almost any aspect of the linguistic system that is variable is a candidate for expressing affect. In other words, language is has a heart as well as a mind of its own. ${ }^{(60)}$

In the environment of online journalism which lacks face to face communication and nonverbal channels which covey affect, affective language can play the same role of nonverbal cues as facial expressions, gestures, body orientation. And that can inspire emotional feelings and the sense of social presence between the writers and their readers.

\section{2-Interactive language:}

The second hypothesis predicted that there are significant differences between readers of an article with an interactive language and readers of the same article without an interactive language according to their levels of social presence, and this hypothesis was tested by Independent - Samples T - test, as I made a comparison between two groups (experimental group and 
control group) the first group read an article that had been written by Interactive language, and the other group read the same article without interactive language (no social language)and after answering a questionnaire, I used T-test to know if there are differences between the two groups or not as follows:

The normality of the two groups has been approved by the test of "Kolmogorov-Smirnov" (p. Value $>0.05$ ) and the homogeneity (Equal variances) was approved too by Levene's Test for Equality of Variances as $(\mathrm{F}=0.167$, Sig. $=0.684)$.

$\mathrm{T}$ - test emphasized that there are significant differences between the experimental group and the control group as $[\mathrm{T}=$ 16.581, $\mathrm{df}=58$, Sig. (2-tailed) $=0.000$ (less than 0.05] .

Table 6

Independent Samples Test

Interactive language and social presence

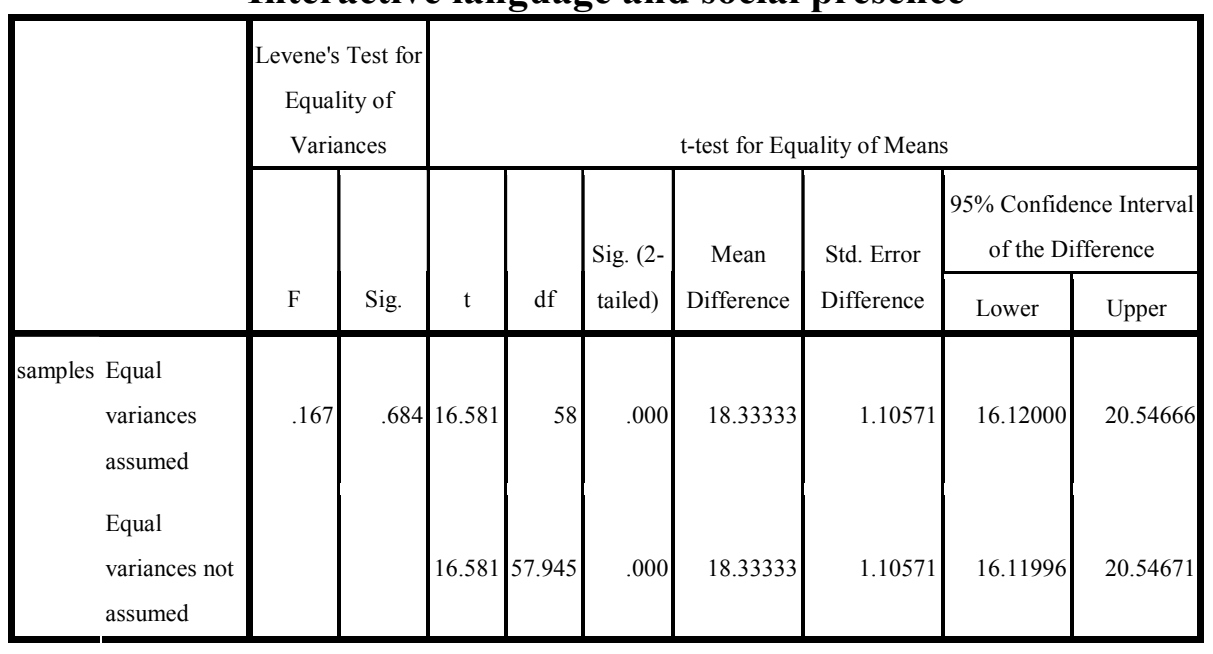

This result confirms that the interactive language can generate the sense of social presence among readers as the Mean of social presence among experimental group was (29.8333) on 
the scale of social presence, but the Mean of social presence among control group was (11.5000).

Table 7

\begin{tabular}{|c|c|c|c|c|}
\hline \multicolumn{5}{|c|}{ Group Statistics } \\
\hline code & $\mathbf{N}$ & Mean & Std. Deviation & Std. Error Mean \\
\hline $\begin{array}{c}\text { samples experimental } \\
\text { group }\end{array}$ & 30 & 29.8333 & 4.34768 & .79377 \\
\hline control group & 30 & 11.5000 & 4.21614 & .76976 \\
\hline
\end{tabular}

According to the experimental group, $\mathrm{T}$ - test confirmed that there are no significant differences between males and females regarding to the role of interactive language in generating social presence. $[\mathrm{T}=-0.593, \mathrm{df}=28$, Sig. $(2$-tailed $)=.558]$.

Table 8

\section{Independent Samples Test}

\section{Interactive language and gender}

\begin{tabular}{|c|c|c|c|c|c|c|c|c|c|}
\hline & \multicolumn{2}{|c|}{$\begin{array}{c}\text { Levene's } \\
\text { Test for } \\
\text { Equality } \\
\text { of } \\
\text { Variances }\end{array}$} & \multicolumn{7}{|c|}{ t-test for Equality of Means } \\
\hline & 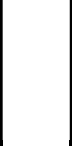 & & & & $\begin{array}{l}\text { Sig. } \\
(2-\end{array}$ & Mean & Std. Error & $\begin{array}{r}95 \% \text { Con } \\
\text { Interval } \\
\text { Differ }\end{array}$ & $\begin{array}{l}\text { fidence } \\
\text { of the } \\
\text { ence }\end{array}$ \\
\hline & $\mathrm{F}$ & Sig. & $\mathrm{t}$ & df & tailed) & Difference & Difference & Lower & Upper \\
\hline $\begin{array}{l}\text { samples Equal } \\
\text { variances } \\
\text { assumed } \\
\text { Equal } \\
\text { variances } \\
\text { not } \\
\text { assumed }\end{array}$ & .205 & .654 & .593 & $\begin{array}{r}28 \\
27.218\end{array}$ & .558 & 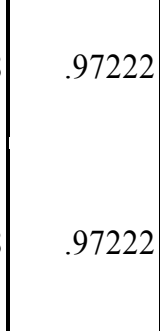 & 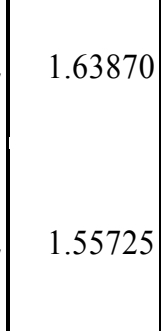 & $-2.38449-$ & 4.32894 \\
\hline
\end{tabular}


The difference between the Mean of social presence among males was (30.2222) and the Mean of social presence among females was (29.2500) and the difference between them is very low.

Table 9

\section{Group Statistics}

\begin{tabular}{|c|c|c|c|c|c|}
\hline & gender & $\mathbf{N}$ & Mean & Std. Deviation & Std. Error Mean \\
\hline \multirow[t]{2}{*}{ samples } & male & 18 & 30.2222 & 4.78423 & 1.12765 \\
\hline & female & 12 & 29.2500 & 3.72034 & 1.07397 \\
\hline
\end{tabular}

The results from this stage in my experiment confirm that interactive language can generate the sense of social presence. This result is very important for online journalism as interactive language agrees with the nature of online journalism which depends greatly on interactivity. The more the feature of interactive language in online journalism, the more the sense of social presence which can narrow the psychological distance between journalists and their readers and that can generate interactivity and participation between journalists and their readers.

\section{3-Cohesive language:}

The third hypothesis predicted that there are significant differences between readers of an article with a cohesive language and readers of the same article without a cohesive language according to their levels of social presence, and this hypothesis was tested by Independent - Samples T - test, as I made a comparison between two groups (experimental group and control group) the first group read an article that had been written by a cohesive language, and the other group read the same article without a cohesive language (non social language) 
and after answering a questionnaire, I used T-test to know if there are differences between the two groups or not as follows:

The normality of the two groups has been approved by the test of "Kolmogorov -Smirnov" (p. Value > 0.05) and the homogeneity (Equal variances) was approved too by Levene's Test for Equality of Variances as $(\mathrm{F}=2.606$, Sig. $=0.112)$.

$\mathrm{T}$ - test emphasized that there are significant differences between the experimental group and the control group as $[\mathrm{T}=$ $16.905, \mathrm{df}=58$, Sig. $(2$-tailed $)=0.000($ less than 0.05$)]$.

Table 10

\section{Independent Samples Test}

Cohesive language and social presence

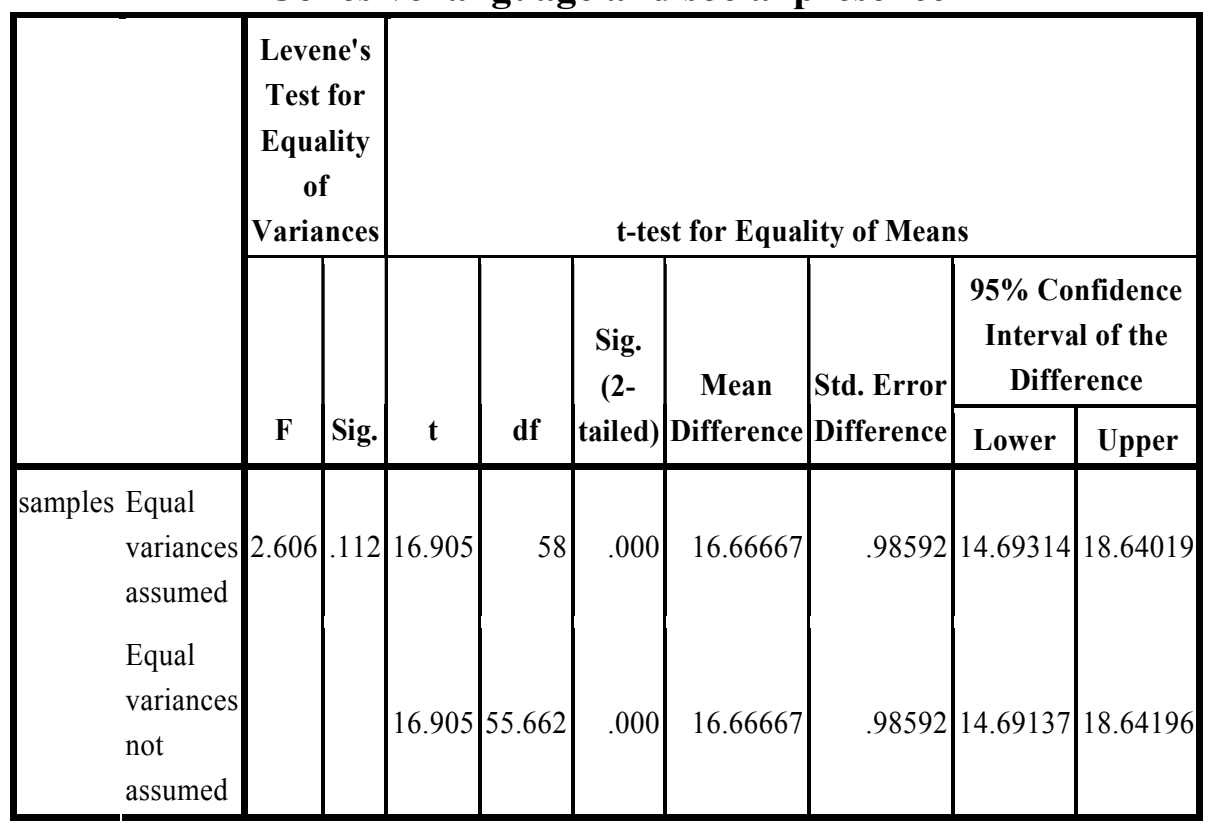

This result confirms that the cohesive language can generate the sense of social presence among readers as the Mean of social presence among experimental group was (29.1667) on 
the scale of social presence, but the Mean of social presence among control group was (12.5000).

Table 11

Group Statistics

\begin{tabular}{|c|c|c|c|c|c|}
\hline & code & $\mathbf{N}$ & Mean & $\begin{array}{c}\text { Std. } \\
\text { Deviation }\end{array}$ & $\begin{array}{l}\text { Std. Error } \\
\text { Mean }\end{array}$ \\
\hline \multirow[t]{2}{*}{ samples } & $\begin{array}{l}\text { experimental } \\
\text { group }\end{array}$ & 30 & 29.1667 & 3.40470 & .62161 \\
\hline & control group & 30 & 12.5000 & 4.19153 & .76527 \\
\hline
\end{tabular}

According to the experimental group, $\mathrm{T}$ - test confirmed that there are no significant differences between males and females regarding to the role of cohesive language in generating social presence. $[\mathrm{T}=-1.360, \mathrm{df}=28$, Sig. $(2$-tailed $)=.185]$.

Table 12

Independent Samples Test

\begin{tabular}{|c|c|c|c|c|c|c|c|c|c|}
\hline & \multicolumn{2}{|c|}{$\begin{array}{c}\text { Levene's Test for } \\
\text { Equality of } \\
\text { Variances }\end{array}$} & \multicolumn{7}{|c|}{ t-test for Equality of Means } \\
\hline & \multirow[t]{2}{*}{$\mathbf{F}$} & \multirow[t]{2}{*}{ Sig. } & \multirow[t]{2}{*}{$\mathrm{t}$} & \multirow[t]{2}{*}{ df } & \multirow[t]{2}{*}{$\begin{array}{l}\text { Sig. (2- } \\
\text { tailed) }\end{array}$} & \multirow[t]{2}{*}{$\begin{array}{c}\text { Mean } \\
\text { Difference }\end{array}$} & \multirow[t]{2}{*}{$\begin{array}{l}\text { Std. Error } \\
\text { Difference }\end{array}$} & \multicolumn{2}{|c|}{$\begin{array}{c}95 \% \text { Confidence } \\
\text { Interval of the } \\
\text { Difference }\end{array}$} \\
\hline & & & & & & & & Lower & Upper \\
\hline $\begin{array}{l}\text { samples Equal } \\
\text { variances } \\
\text { assumed }\end{array}$ & 2.890 & .100 & $-1.360-$ & 28 & .185 & $-1.66667-$ & 1.22539 & $-4.17677-$ & .84344 \\
\hline $\begin{array}{l}\text { Equal } \\
\text { variances not } \\
\text { assumed }\end{array}$ & & & $-1.360-$ & 21.848 & .188 & $-1.66667-$ & 1.22539 & $-4.20900-$ & .87567 \\
\hline
\end{tabular}

The difference between the Mean of social presence among males was (28.3333) and the Mean of social presence among females was (30.0000) and the difference between them is low. 
Table 13

Group Statistics

\begin{tabular}{|rl|r|r|r|r|}
\hline & Gender & N & Mean & Std. Deviation & Std. Error Mean \\
\hline samples & male & 15 & 28.3333 & 4.15188 & 1.07201 \\
& female & 15 & 30.0000 & 2.29907 & .59362 \\
\hline
\end{tabular}

The results of this stage in my study confirm that cohesive language can generate the sense of social presence, and that result is important for the language of online journalism as cohesive language combines readers with journalists. This feature of writing depends on the base that online journalism is a platform which combines journalists and readers to interact and exchange information and opinions.

Online journalism focuses on roles exchanging between journalists and readers in a two - way communication model. If journalists want to interact with their audiences concerning the raised topics, they should use the cohesive language which makes readers feel that they are included in the circle of discussion, and that is an important linguistic trend that should be applied in online journalism.

\section{4- The effect of all the types of social language:}

The fourth hypothesis predicted that there are significant differences between readers of an article with all the three types of the social language and readers of the same article without social language according to their levels of social presence, and this hypothesis was tested by Independent - Samples T - test, as I made a comparison between two groups (experimental group and control group) the first group read an article that had been written by the three categories of social language, and the other group read the same article without these categories (non social language) and after answering a questionnaire, I used T-test to 
know if there are differences between the two groups or not as follows:

The normality of the two groups has been approved by the test of "Kolmogorov -Smirnov" (p. Value > 0.05) and the homogeneity (Equal variances) was approved too by Levene's Test for Equality of Variances as $(\mathrm{F}=0.013$, Sig. $=0.909)$.

$\mathrm{T}$ - test emphasized that there are significant differences between the experimental group and the control group as $[\mathrm{T}=$ 18.476, $\mathrm{df}=58$, Sig. $(2$-tailed $)=0.000($ less than 0.05$)]$.

Table 14

\section{Independent Samples Test}

All types of social language and social presence

\begin{tabular}{|c|c|c|c|c|c|c|c|c|c|}
\hline & \multicolumn{2}{|c|}{$\begin{array}{l}\text { Levene's } \\
\text { Test for } \\
\text { Equality } \\
\text { of } \\
\text { Variances }\end{array}$} & \multicolumn{7}{|c|}{ t-test for Equality of Means } \\
\hline & \multirow[b]{2}{*}{$\mathbf{F}$} & \multirow[b]{2}{*}{ Sig. } & \multirow[b]{2}{*}{$\mathbf{t}$} & \multirow[b]{2}{*}{ df } & \multirow{2}{*}{\begin{tabular}{|c|} 
Sig. \\
$(2-$ \\
tailed $)$
\end{tabular}} & \multirow{2}{*}{$\begin{array}{c}\text { Mean } \\
\text { Difference }\end{array}$} & \multirow{2}{*}{$\begin{array}{l}\text { Std. Error } \\
\text { Difference }\end{array}$} & \multicolumn{2}{|c|}{\begin{tabular}{|c}
$95 \%$ Confidence \\
Interval of the \\
Difference \\
\end{tabular}} \\
\hline & & & & & & & & Lower & Upper \\
\hline $\begin{array}{l}\text { samples Equal } \\
\text { variances } \\
\text { assumed } \\
\text { Equal } \\
\text { variances } \\
\text { not } \\
\text { assumed }\end{array}$ & .013 & .909 & $\begin{array}{l}18.476 \\
18.476\end{array}$ & 58 & $\begin{array}{l}.000 \\
\\
.000\end{array}$ & 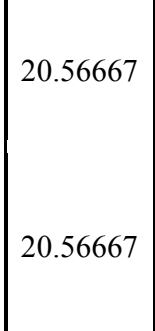 & 1.11316 & 18.33844 & 22.79489 \\
\hline
\end{tabular}

This result confirms that the social language can generate the sense of social presence among readers as the Mean of social presence among experimental group was (32.3333) on the scale of social presence, but the Mean of social presence among control group was (11.7667). 
Table 15

\section{Group Statistics}

\begin{tabular}{|c|l|l|r|r|}
\hline code & N & Mean & Std. Deviation & Std. Error Mean \\
\hline samples experimental group & 30 & 32.3333 & 4.33378 & .79124 \\
control group & 30 & 11.7667 & 4.28858 & .78298 \\
\hline
\end{tabular}

According to the experimental group, T- test confirmed that there are no significant differences between males and females regarding to the role of social language in generating social presence. $[\mathrm{T}=-1.250, \mathrm{df}=28, \mathrm{Sig}$. $(2$-tailed $)=.221]$.

Table 16

Independent Samples Test

All types of social language and gender

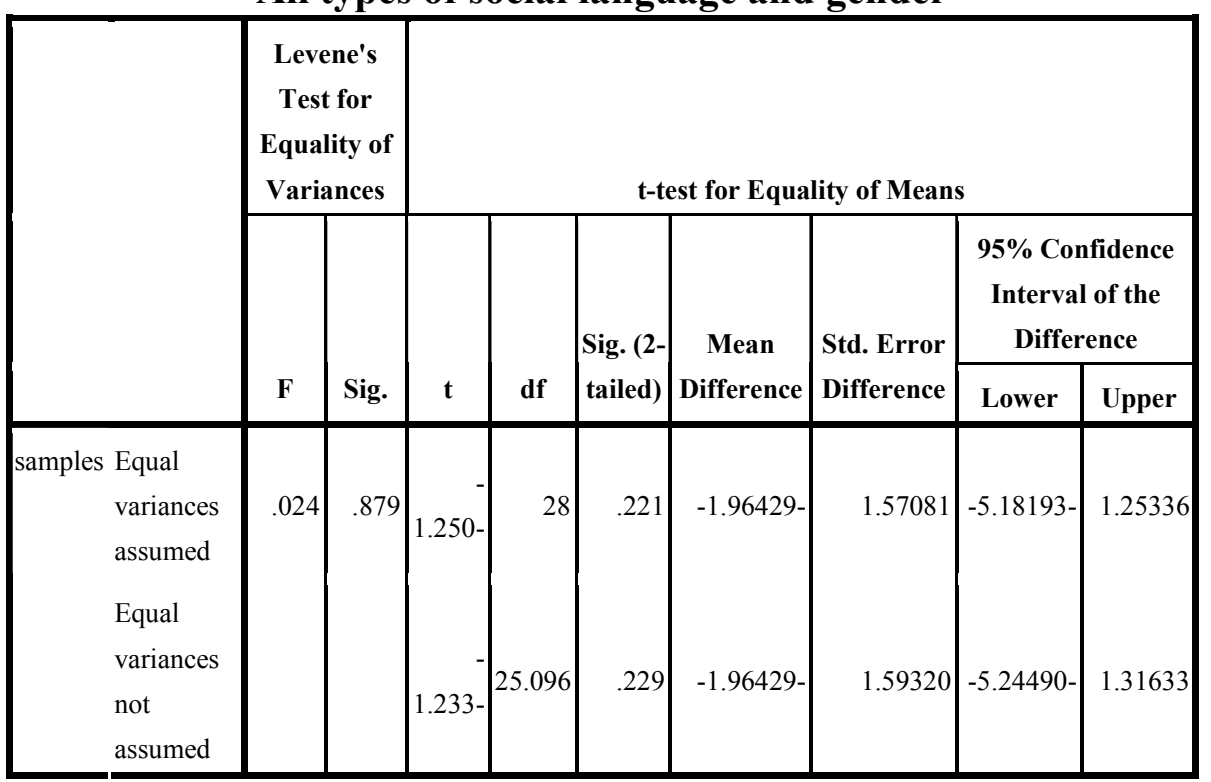

The Mean of social presence among females was (33.2500) the Mean of social presence among males (31.2857) and difference between them is low. 
Table 17

\begin{tabular}{|c|c|c|r|r|}
\hline \multicolumn{5}{|c|}{ Group Statistics } \\
\hline gender & $\mathbf{N}$ & Mean & Std. Deviation & Std. Error Mean \\
\hline samples male & 14 & 31.2857 & 4.74631 & 1.26851 \\
female & 16 & 33.2500 & 3.85573 & .96393 \\
\hline
\end{tabular}

In this stage in my experiment, the results confirmed that using the three types of social language can generate the sense social presence among readers. Using most of the features of social language in online journalism can inspire the sense of social presence among readers, and that can encourage them to participate and interact with journalists, the matter that can help in building up public spaces concerning public issues.

\section{5- Variance among the 4 manipulations:}

The fifth hypothesis predicted that there are significant differences among the four experimental groups who are exposed to different types of social language according to their levels of social presence.

To know if there are differences among the four manipulations (affective language - interactive language cohesive language - all the categories) in generating the sense of social presence among readers, I used a One- Way ANOVA, and here are the results:

Table 18

one - way ANOVA among experimental groups

\begin{tabular}{|l|l|l|l|l|l|}
\hline Source of variance & Sum of Squares & df & Mean Square & F & Sig. \\
\hline Between Groups & 1084.033 & 3 & 361.344 & 16.378 & 0.000 \\
\hline Within Groups & 2559.267 & 116 & 22.063 & - & - \\
\hline Total & 3643.300 & 119 & - & - & - \\
\hline
\end{tabular}


According to table (1) there are significant differences among the four groups as $(\mathrm{P}$. value $<0.05)$ and to know the sources of these differences, I made a post Hoc by LSD test and the results were as here:

Table 19

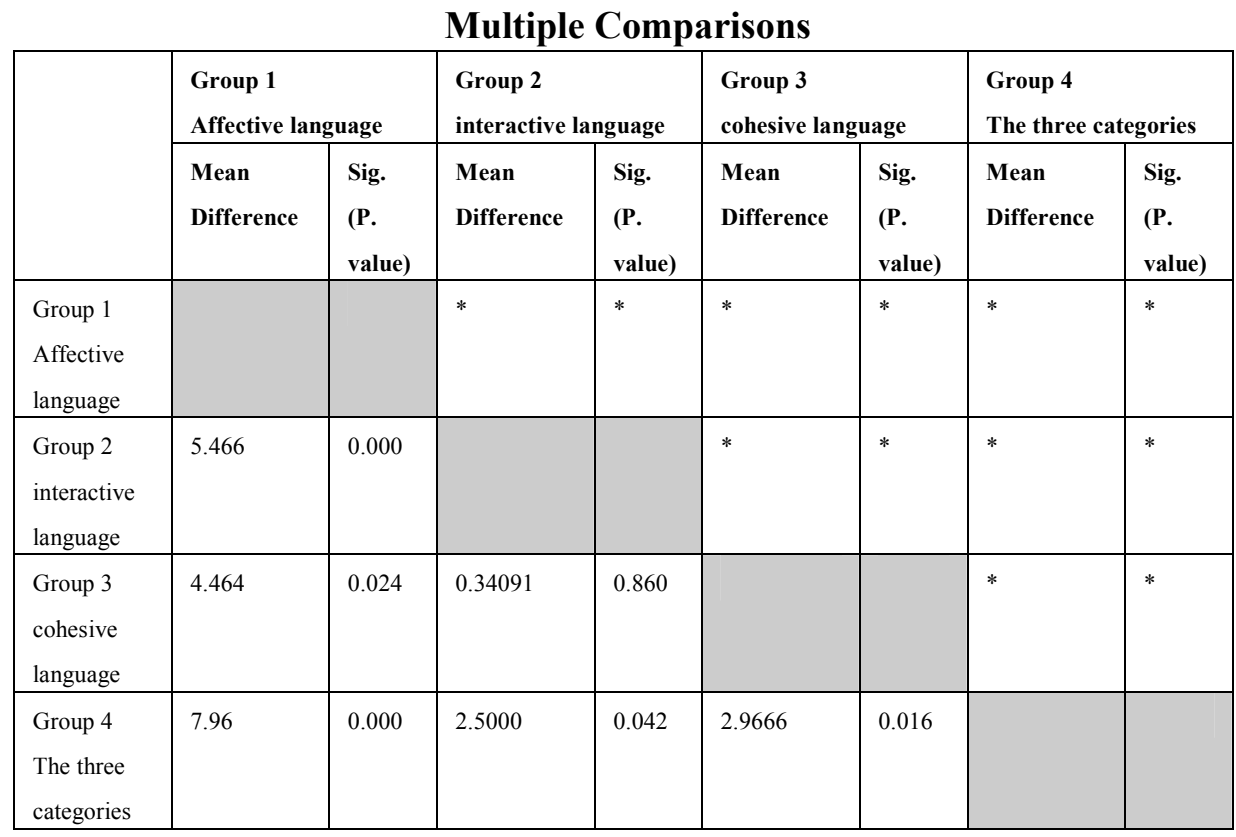

It has been noticed that there are significant differences between group 1 (those who exposed to affective language) and both of group 2 (interactive language) and group 3 (cohesive language) for the behalf of the second and third groups. That means both of interactive and cohesive language can generate the sense of social presence more than affective language, and this agrees with the nature of online journalism which based on interactivity and using interactive and cohesive language can encourage readers to interact with journalists.

It has been noticed that there no significant differences between group 2 (interactive language) and group 3 (cohesive 
language), as both of them inspire a high level of social presence. The use of both of them in the language of online journalism can compensate the lack of nonverbal cues in communication.

It has been noticed that there are significant differences between group 4 (who are exposed to the three types of social language) and all the rest groups for the sake of the fourth group, and this means that combining all the characteristics of social language in an article can exaggerate the sense of social presence among readers. Journalists should be aware of the importance of the three types of social language, as using it can make their style more attractive to the audience and help them in building interactive communities or public spaces.

Using social language can inspire effective participation among readers, and that may help in building good opinions about salient topics in the society, and thus online journalism can help in building public spheres related to the main topics of the society.

\section{6- The effect of social language after excluding the effect of both of introversion and involvement:}

The sixth hypothesis predicted that there are significant differences between readers of articles with social language and readers of the same articles without social language according to their levels of social presence after excluding the effect of both of introversion and involvement.

To test this hypothesis I followed the following steps:

Firstly, I measured the correlation between social presence and both of the control variables to be sure that there a relationship between social presence and each of control variables using Pearson correlation. 
Secondly, I used ANCOVA to exclude the effect of the control variables, and here are the results:

There is a significant correlation between social presence and involvement among students at the 0.05 level (2-tailed), so we should exclude the effect of this control variable to be sure about the effect of social language and social presence among students.

Table 20

\section{Correlations}

\begin{tabular}{|ll|c|c|}
\hline & & social presence & involvement \\
\hline social presence & Pearson Correlation & 1 & $.141^{*}$ \\
& Sig. (2-tailed) & & .028 \\
& N & 240 & 240 \\
\hline involvement & Pearson Correlation & $.141^{*}$ & 1 \\
& Sig. (2-tailed) & .028 & \\
& N & 240 & 240 \\
\hline
\end{tabular}

*. Correlation is significant at the 0.05 level (2-tailed).

There is a significant correlation between social presence and introversion among students at the 0.05 level (2-tailed), so we should exclude the effect of this control variable to be sure about the effect of social language and social presence among students. 
Table 21

Correlations

\begin{tabular}{|c|c|c|c|}
\hline & & social presence & introversion \\
\hline \multicolumn{2}{|c|}{ social presence Pearson Correlation } & 1 & $.507^{* *}$ \\
\hline & Sig. (2-tailed) & & .000 \\
\hline & $\mathrm{N}$ & 240 & 240 \\
\hline \multirow[t]{3}{*}{ introversion } & Pearson Correlation & $.507^{* *}$ & 1 \\
\hline & Sig. (2-tailed) & .000 & \\
\hline & $\mathrm{N}$ & 240 & 240 \\
\hline
\end{tabular}

**. Correlation is significant at the 0.01 level (2-tailed).

I used ANCOVA to measure the effect of social language on social presence after excluding the effect of both the involvement and introversion, and P. Value was [88.706 sig. 0.01 ] and that means social language can affect social presence among readers.

Table 22

Tests of Between-Subjects Effects

\begin{tabular}{|l|r|r|r|r|r|}
\hline Dependent Variable: social presence & & & \\
\hline Source & $\begin{array}{c}\text { Type III Sum of } \\
\text { Squares }\end{array}$ & df & $\begin{array}{c}\text { Mean } \\
\text { Square }\end{array}$ & F & Sig. \\
\hline $\begin{array}{l}\text { Corrected } \\
\text { Model }\end{array}$ & $16501.355^{\mathrm{a}}$ & 9 & 1833.484 & 102.075 & .000 \\
\hline Intercept & 1526.374 & 1 & 1526.374 & 84.977 & .000 \\
\hline introversion & 31.409 & 1 & 31.409 & 1.749 & .187 \\
\hline involvement & 18.460 & 1 & 18.460 & 1.028 & .312 \\
\hline Social Language & 11153.539 & 7 & 1593.363 & 88.706 & .001 \\
\hline Error & 4131.308 & 230 & 17.962 & & \\
\hline Total & 116273.000 & 240 & & & \\
\hline Corrected Total & 20632.663 & 239 & & & \\
\hline
\end{tabular}

a. R Squared $=.800($ Adjusted $R$ Squared $=.792)$ 


\section{Conclusion:}

Since the development of the internet, there is a great attention and focus on social presence in online environment. The idea is that a medium's social effects are principally caused by the degree of social presence which it affords to its users. By social presence is meant a communicator's sense of awareness of the presence of an interaction partner. This is important for the process by which man comes to know and think about other persons, their characteristics, qualities and inner states.

Social presence can play an important role in building trust processes and the sense of warmth and belonging, both necessary to establish the ideal climate for participation and interactivity with writers in online environment.

Some researchers approved that we can generate the sense of social presence in online environments which lacks nonverbal cues by alternative cues most of it are linguistic cues, and that what has been approved by this study.

The internet has revolutionized the way we live our lives in untold ways, but the most far-reaching is the impact it is having on the way we communicate. Media language should be developed to adapt to that change. Media language should be adaptive to be something more than a dry account of the events of the day. Social language is one important way to achieve that goal.

As we know the most important feature of the internet is its interactivity which narrows the distance between readers and journalists. On the other hand, the development of blogs and online social networks made radical changes in the environment of journalism as journalists became aware to be sociable with their readers to be able to compete with these new media. 
In the age of social media, journalists should be sociable and they can narrow the institutional distance between them and their readers through social language

It is inconceivable to think that one could create a community without some degree of social presence and that what social language can do in the environment of online journalism.

Journalists should learn and tackle the successful strategies for using social language in online environment as it may inspire the audience to participate and interact with journalists.

This strategy can help journalists to build up their public spaces with their readers and exchange opinions among them and that can enrich the role of online journalism in building up and constructing public opinion in society.

To sum up, online journalism should adopt the style of social language and encourage journalists to use it in their writings. And that can be done by distributing style books which explain this type of writing and its features. The Egyptian Syndicate can play a great role in that domain.

Finally, this study focused on the role of social language in generating social presence in online journalism which encourages the engagement between writers and their readers.

Still, more research should be conducted regarding the impact of social language on audience participation and credibility of online journalism. 


\section{$\underline{\text { References: }}$}

1 - Conboy, M. (2010). The Language of Newspapers: socio-historical perspectives. New York: Continuum international Publishing Group, Pp.2-3.

2 - Rosen, J. (2004).Top ten ideas of '04: News turns from a lecture to a conversation. Retrieved March 19, 2011, from http://archive.pressthink.org/2004/12/29/ tp04_lctr. html.

3 - Conboy, M., op. cit, Pp.2-3.

4 - Nass, C., \& Moon, Y. (2000). Machines and mindlessness: Social responses to computers. Journal of Social Issues, Volume 56, No. 1, pp. 81-103.

5 - Potter, A. (2004), Interactive rhetoric for online learning environments, The Internet and Higher Education, Volume 7, No.3, Pp.183-198.

6 - Shechtman, N., \& Horowitz, L. M. (2003). Media inequality in conversation: How people behave differently when interacting with computers and people. Proceedings of the conference on human factors in computing systems, New York: ACM Press, pp. 281-288.

7 - Kraut, R., et.al. (1998). Internet paradox: A social technology that reduces social involvement and psychological well-being, American Psychologist, Volume 53, No.9, 1017-1031.

8 - Aragon, S. R. (2003, Winter). Creating social presence in online environments. New Directions for Adult and Continuing Education, 100, $57-68$

- Baron, N. S. (1998). Writing in the age of email: The impact of ideology versus technology. Visible Language, Volume 32, No.1, p35-53.

9 - Gillmor, D. (2004) : "We the Media: Grassroots Journalism by the People, for the People" (USA: O'Reilly Media), pp. XII.

10- Hamman, B. (2006): "Two voices: social presence, participation, and credibility in online news" unpublished master thesis, University of Missouri- Columbia , pp. 2-3, pp.39-49).

11- Cotter, C. (2010), "News Talk: investigating the language of journalism", (New York, Cambridge university press), p.201. 
12 - Gumperz, J. and Cook-Gumperz,J. (2008) "Studying language, culture, and society: Sociolinguistics or linguistic anthropology?" Journal of Sociolinguistics, Volume12, No.4, pp. 532-545.

13 - Hamman, B., op. cit, p.10.

14 - Garrison, D.R., et. al (2000) Critical inquiry in a text-based environment: computer conferencing in higher education. The Internet and Higher Education, 2, pp. 87-105.

15 - Rourke, L., et al., (2001). Assessing social presence in asynchronous, text-based, computer conferencing. Journal of Advertising, Volume 14, No. 3, pp. 50-71.

- Swan, K. (2002). Building learning communities in online courses: The importance of interaction. Education, Communication \& Information, volume 2, No. 1, 23-49.

16 - Rourke, L., et al., op cit., pp. 50-71.

- Lomicka, L. and Lord, G. Social presence in virtual communities of foreign language (FL) teachers, system, volume 35, No. 2, pp, 208-228.

17 - Garrison D.R., et al. (2000) "Critical inquiry in a text-based environment: computer conferencing in higher education". The Internet and Higher Education, Volume 2, No. (2-3), pp. 87-105.

18 - Walther, J.B. (1992). Interpersonal effects in computer-mediated interaction: A relational perspective. Communication research, Volume 19, No. 1, pp. 52-90.

19 - Choi, Y. (1995), The effect of social and physical distance on the global communication networks, International Communication Gazette, volume 54, No. 2, pp.163-192.

20 - Murphy, K. L., \& Collins, M. P. (1997). Development of communication conventions in instructional electronic chats. Journal of distance education, Volume 12, No. (1/2), pp. 177-200.

21 - Wang, Y-M., (1998). Email dialogue journaling in an English as a second language (ESL) reading and writing classroom. International Journal of Educational Telecommunications, Volume 4, pp. 263-287.

22 - Danchak, M. M., et al., (2001). Presence in mediated instruction: bandwidth, behavior, and expectancy violations. Paper presented at the 
7th Sloan-C international conference on asynchronous learning networks (ALN), Orlando, FL, pp. 17-19.

23 - Abrams, Z. (2001). Computer-mediated communication and group journals: Expanding the repertoire of participant roles. System, Volume 29, pp. 489-503.

24 - Stein, D. S. and Wanstreet, C. E. (2003). Role of Social Presence, Choice of Online or Face-to-Face Format, and Satisfaction with Perceived Knowledge Gained in a Distance Learning Environment. Paper presented at the Midwest Research to Practice Conference in Adult, Continuing and Community Education. [Online at:

http://www.alumniosu. org/ Midwest \%20

papers/Stein\%20\&\%20Wanstreet-Done.pdf] (Retrieved: 16 December, 2011).

25 - Steve, w. (2005) Creating Social Presence in Digital Learning Environments: A Presence of Mind? , Paper presented at the TAFE Conference, Queensland, Australia. [ Online at: http://videolinq.tafe.net /learning2005/papers/wheeler.pdf] (Retrieved on 17 December, 2011).

26 - Hamman, B., op. cit.

27 - Wolitzky, R. A. (2014) "Affective Language and Attitudes Toward Public Policy" unpublished dissertation, The City University of New York.

28 - Gunawardena, C. N. (1995). Social presence theory and implications for interaction and collaborative learning in computer conferences. International journal of educational telecommunications, Volume 1, No. (2/3), PP. 147-166.

29 - Walther, J.B., op. cit, PP. 52-90.

30 - Rice, R.E. (1993). Media appropriateness: Using social presence theory to compare traditional and new organization media. Human communication research, Volume 19, No. 4, PP. 451-484.

31 - Gunawardena, C. N., op. cit, PP. 147-166.

32 - Stein, D. S. and Wanstreet, C. E. (2003) Role of Social Presence, Choice of Online or Face-to-Face Format, and Satisfaction with Perceived Knowledge Gained in a Distance Learning Environment. Paper presented at the Midwest Research to Practice Conference in Adult, Continuing and Community Education. [available on: 
http://www.alumniosu. org/ Midwest \%20

papers/Stein\%20\&\%20Wanstreet-Done.pdf] (Retrieved on July 11, 2011).

33 - Lowenthal, P. R. (2009). The evolution and influence of social presence theory on online learning. In T. T. Kidd (Ed.), Online education and adult learning: New frontiers for teaching practices, (Hershey, PA: IGI Global). pp. 124-139.

34 - Kehrwald, B. (May, 2008). Understanding Social Presence in TextBased Online Learning Environments. Distance Education, Volume 29, No. 1, PP. 89-106.

35 - Tu, C.H., and McIssac, M.. (2002). The relationship of social presence and interaction in online classes. The American journal of distance education, volume16, No.3, PP. 131-150.

36 - Lee, K. M., and Nass, C. (2003). Designing social presence of social actors in human computer interaction. Letters of the CHI, volume 5, No.1, PP. 289-296.

37- Rice, R.E., op. cit., PP. 451-484.

38- Gunawardena, C. N., op. cit, PP. 147-166.

39 - Skalski, P., Tamborini, R., Glazer, E., \& Smith, S. (2009). Effects of humor on presence and recall of persuasion messages. Communication Quarterly, 57(2), 136-153.

- Skalski, P. \& Tamborini, R. (2007). The role of social presence in interactive agent-based persuasion. Media Psychology, 10(3), 385-413.

- Biocca, F., et al. (2003). Toward a more robust theory and measure of social presence: review and suggested criteria, Presence: Teleoperators and Virtual Environments, Volume 12, No.5, PP. 456-480.

40 - Sallnas, E.L., et. al., (2000). Supporting presence in collaborative environments by haptic force feedback. ACM Transactions on Computer-Human Interaction, volume 7, No., 4, PP. 461-476.

41 - Gunawardena, C. N., op. cit, PP. 147-166.

- Swan, K., op. cit., PP.23-49.

42 - Baym, N. K. (1995). The emergence of community in computermediated communication. In S. G. Jones (Ed.), Cybersociety: Computer- 
mediated communication and community (Thousand Oaks, CA: Sage) pp. 138-163.

43 - Rodgers, S., and Chen, Q. (2005). Internet community group participation: Psychosocial benefits for women with breast cancer. Journal of Computer Mediated Communication, Volume 10, No. 4, article 5.

44 - Hian, L. B., et. al., (2004). Getting to know you: Exploring the development of relational intimacy in computer-mediated communication. Journal of Computer Mediated Communication, Volume 9, No. 3, [ available on: http://jcmc.indiana.edu/vo19/issue3/detenber.html] ( Retrieved Feb 20, 2012).

45- Hwang, H. (2005). Predictors of instant messaging: Gratifications sought, gratifications obtained, and social presence. Paper presented at the International Communication Association Annual Conference, New York, NY.

46 - Walther, J.B., op. cit, PP. 52-90.

47 - Baym, N. K., op. cit., pp. 138-163.

48 - Hu, Y., et. al., (2005). Friendships through im: examining the relationship between instant messaging and intimacy. Journal of Computer Mediated Communication, Volume 10, No. 1, [Available on: http://jcmc.indiana.edu/vol10/issue1/detenber.html] (Retrieved Feb 20, 2012).

49 - Conaway, R. N., et. al., (2005). Strategies for enhancing student interaction and immediacy in online courses. Business Communication Quarterly, Volume 68, No. 1, PP. 23-35.

50 - Honeycutt, C. (2005). Hazing as a process of boundary maintenance in an online community, Journal of Computer Mediated Communication, 10(2). [Available on: http://jcmc. indiana.edu /vol10/issue2 /detenber.html] (Retrieved Feb 20, 2012).

51 - Preece, J. (2001). Sociability and usability in online communities: Determining and measuring success. Behavior and Information Technology, Volume 20, No. 5, PP. 347-356.

- Preece, J., \& Maloney-Krichmar, D. (2005). Online communities: Design, theory, and practice. Journal of Computer - Mediated Communication, 
Volume 10, No. 4. [Available on: http://jcmc. indiana.edu /vol10/issue4 /detenber.html] (Retrieved Feb 20, 2012).

52 - Murphy, K. J. \& Collins, M. P. (1997). Communication conventions in instructional electronic chats. First Monday, Volume 2, No. 11, [Available on: http://www. firstmonday .dk/issues /issue 2_11/murphy] (Retrieved October 17, 2012)

- Ng, E. \& Detenber, B. (2005). The impact of synchronicity and civility in online political discussions on perceptions and intentions to participate. Journal of Computer-Mediated Communication, Volume 10, No.3. [Available on: http://jcmc. indiana.edu /vol10/issue3 /detenber.html] (Retrieved Feb 20, 2012).

53 - Danchak, M. M., et. al., (2001, November). Presence in mediated instruction: Bandwidth, behavior, and expectancy violations. Paper presented at the annual meeting of the Asynchronous Learning Networks, Orlando, FL.

54 - McMillan, S. J., et. al., (2003). Effects of structural and perceptural factors on attitude toward the website. Journal of Advertising Research, volume 43,PP. 400 - 409.

55 - Zaichkowsky, J. L. (1985). Measuring the involvement construct. Journal of Consumer Research, 12, 3441-352. Quted from: Matthew Thomson, et al.(2005) . The Ties That Bind: Measuring the Strength of Consumers' Emotional Attachments to Brands. Journal of Consumer Psychology, Volume 15, No., 1, PP. 77-91.

56- Thompson, E. R. (October, 2008) " Development and Validation of an International English Big-Five Mini-Markers Personality and Individual Differences, Volume 45, No.6, PP. 542-548.

57 - McCroskey, J. C. (1997). Self-report measurements. In J. A. Daly, et al. Avoiding Communication: Shyness, Reticence, \& Communication Apprehension, (Cresskill, NJ: Hampton Press) pp. 191 -216.

- McCroskey, J.C., and Beatty, M.J. (1998). Communication Apprehension. In J.C. McCroskey, et. al. (Eds.), Communication and Personality: trait perspectives (Cresskill, NJ: Hampton Press) PP. 215 -231.

58 - Dr. Mohammed Saad, a professor of journalism, Mass Communication Department, Faculty of Arts, ElMenia University. 
59 - Wolitzky, Rachel A.(2014) " Affective Language and Attitudes Toward Public Policy" unpublished dissertation, The City University of New York, pp1-.3.

60 - Ochs, E. and Schieffelin, B. (1989) "Language has a heart", Text, Vol. 9, No., 1. Pp. 7-25. 